\title{
Priming a Cross-Category Brand Alliance: The Moderating Role of Attribute Knowledge and Need for Cognition
}

\author{
Laura Smarandescu \\ Iowa State University \\ Randy Rose \\ University of South Carolina \\ Douglas H. Wedell \\ University of South Carolina
}

\begin{abstract}
Firms often enter cross-category advertising brand alliance strategies with the goal to increase their market share by association with popular but noncompeting brand allies. However, firms are often not aware of the effects of these alliances on consumer perceptions of participating brands. This research explores the factors moderating brand attribute inferences following exposure to a cross-category advertising brand alliance. It is proposed that attributes of a brand ally may serve as anchors that produce assimilation effects and move perceptions of a target brand toward the ally's attribute value, or as standards of comparison that produce contrast. This work provides evidence that attribute judgments in a cross-category advertising brand alliance are moderated by attribute knowledge and individual differences in information processing motivation as reflected in self-reported need for cognition (NFC) ratings. (C) 2013 Wiley Periodicals, Inc.
\end{abstract}

The past decade witnessed a strong increase in different forms of inter-firm cooperation such as joint ventures, ingredient branding, brand alliances, and crosspromotions. This research focuses on an increasingly popular form of advertising brand alliance that links brands from different product categories that share a common goal. Some marketplace examples of crosscategory advertising brand alliances include Starbucks allied with Hewlett Packard, Nike and iPod, Kellogg's and Tropicana, and AOL paired with American Airlines. Although the brand association in these crosscategory alliances may be surprising to consumers due to little similarity between the associated product categories, this work shows that these alliances can serve as efficient tools for brand repositioning as they may boost consumer perceptions of brand attributes. Nonetheless, marketplace examples suggest that these strategies should be used with caution since such alliances may also hurt participating brands. For example, when H\&R Block participated in a joint advertising campaign with Excedrin, the association with migraine headaches resulted in negative press for H\&R Block (The Wall Street Journal, 1991).

Previous work on brand alliance strategies looked at the effect of a brand alliance on overall attitudes toward participating brands (Lafferty, 2009; Levin \& Levin, 2000; Rao \& Ruekert, 1994; Rao et al., Simonin \& Ruth, 1998; Walchli, 2007). Simonin and Ruth (1998) found that consumer attitudes toward a brand alliance influence subsequent attitudes of each brand partner and that familiarity with the brand moderates the strength of the effects observed on individual brands. Levin and Levin (2000) show that a brand ally may serve as context for the judgment of a target brand and have an assimilation effect on overall attitudes toward a target. Hence, after exposure to information about a brand ally consumers' overall evaluation of the target brand shifted toward the evaluation of the ally. In a cobranding context Walchli (2007) found that individuals' level of elaboration on the rationale of the brand partnership moderated the relationship between perceived congruity of the brand partners and overall product 
evaluation. Although past research has examined the effect of brand alliances on overall attitudes toward associated brands, less is known about the effect of crosscategory brand alliances on consumer perceptions of brand attributes, or whether these alliances may affect attribute repositioning. Most research investigating attribute repositioning has been performed in the context of comparative advertising and shows that explicit attribute comparisons with a brand leader from the same product category can affect attribute perceptions of a target brand. An example of a typical comparative advertising claim would be a new dish soap brand $\mathrm{X}$, claiming that it is gentler on hands than Palmolive, the category leader. Other approaches that examined the effect of context at brand attribute level include research on multiple cues (Miyazaki, Grewal, $\&$ Goodstein, 2005) and research exploring the role of context in retailing (Buchanan, Simmons, \& Bickart, 1999). These approaches differ from the present research as they looked at attribute inferences made within the same brand, or product category. However, the present research investigates a theoretically novel question, whether the mere priming of a cross-category brand linkage may affect attribute perceptions of a target brand in the absence of an explicit attribute comparison and when the compared brands belong to different product categories. An example of priming a brand linkage would be Hewlett Packard advertising with Dreamworks using the visual tagline: HP + Dreamworks. This work further examines the boundary conditions when such brand alliances may help or hurt target brand attribute perceptions.

It is proposed that priming a brand linkage in a cross-category brand alliance ad affects subsequent judgments of brand attributes due to a mechanism related to how contextual information is used in judgment. This research suggests that attributes of a brand ally may serve as anchors that produce assimilation effects and move perceptions of a target brand toward the contextual brand's (ally) attribute value, or they may serve as standards of comparison that produce contrast and move perceptions of the target away from the ally's attribute value. It is also proposed that the inference processes occurring at exposure to cross-category brand alliances are moderated by knowledge about brand attributes and by individual differences in information processing motivation as reflected in self-reported need for cognition (NFC) ratings.

This paper is organized as follows. First, the theoretical paradigm is introduced and the role of context in cross-category advertising brand alliances is discussed. Two context effects, contrast and assimilation are introduced. Second, evidence is presented that the effect of a brand alliance prime is moderated by attribute knowledge as reflected in attribute alignability, which is the degree to which target and ally brand attribute levels are accessible in memory and can be directly compared. Third, it is proposed that individual differences in processing motivation as reflected in NFC measures moderate the effects of the brand alliance prime on at- tribute judgments. Study 1 examines the moderating role of NFC on target attribute judgments following exposure to a brand alliance prime and provides a direct test for the effect of attribute knowledge using a manipulation of attribute alignability (Markman \& Gentner, 1993; Zhang, Kardes, \& Cronley, 2002; Zhang \& Markman, 2001). Study 2 further examines the effect of attribute knowledge on attribute judgment following exposure to a brand alliance prime in a more ecologically valid context when well-known brands with distinct mental representations are associated and individuals resort to information stored in long-term memory to make attribute evaluations. Finally, implications of this research for marketing managers and directions for future research are discussed.

\section{BACKGROUND LITERATURE}

Consumer inference processes at exposure to brand or product associations have been investigated by several research streams in marketing including research in brand extensions, comparative advertising, ingredient branding, bundling, and work on multiple cues. Although these research streams may be informative with respect to the factors affecting attribute judgment following exposure to a cross-category advertising brand alliance, they differ from the present research paradigm in important ways. First, research on brand extensions suggests that consumers' existing knowledge about a parent brand can extend to new products sharing the same brand name through an associative network process (Aaker \& Keller, 1990; Bambauer-Sachse, Hüttl, \& Gierl, 2011; Loken \& John, 1993). However, brand extension research does not make predictions whether the same associative network model applies to inferences made when different brands with distinct memory schemas are linked in an advertisement. Second, work in comparative advertising (Droge \& Darmon, 1987; Gorn \& Weinberg, 1984; Rose, Miniard, Barone, Manning, \& Till, 1993; Sujan $\&$ Dekleva, 1987) investigated the attribute inferences made when individuals are exposed to explicit comparisons between brands belonging to the same product category (e.g., Tide detergent vs. Sunlight), sharing several attributes. However, comparative advertising research does not make useful predictions for the inferences occurring when brands from different product categories with no shared attributes are associated in an ad (e.g., Starbucks and Hewlett Packard), and in the absence of an explicit comparison. Research in ingredient branding (Park, Jun, \& Shocker, 1996) has examined inferences taking place when brands from the same superordinate category level, but different subordinate level categories are integrated in the same product (e.g., HP computer with Intel chip inside). These models are not relevant to the present research since products associated in a cross-category advertising alliance are not integrated into the same product as required by ingredient branding, and belong to different 
superordinate level categories (e.g., Nike shoes and iPod music players). Furthermore, research in bundling (Yadav, 1994) examined consumer inferences when exposed to bundles, but the focus there was on product category rather than brand level inferences, and the outcome measures were overall evaluations of the bundle and products in the bundle rather than brand level attribute judgments. Finally, Buchanan, Simmons, and Bickart (1999) examined the effect of the immediate context of other brands on judgments of a target in a retail environment and focused on within category brand judgments. This research differs from the present approach as no brand linkage is primed, and the target brands belong to the same product category.

To summarize, the theoretical contribution of the present research paradigm is distinct from the above models as it examines the effect of a cross-category brand alliance prime on subsequent brand attribute judgments. Thus, individuals in the present studies are exposed to a brand association, where the linkage between brands is being emphasized, rather than a particular brand name or attribute (as emphasized by brand extension, respectively, comparative advertising strategies), and brand attribute perceptions are subsequently measured. The effect of the brand alliance exposure (i.e., prime) on subsequent brand attribute judgments is attributed to the recent context. It is also proposed that the effect of the brand alliance prime on attribute judgment is moderated by attribute knowledge and information processing motivation as measured by NFC. Each of these factors is discussed further.

\section{The Role of Context in Judgment}

Context plays an important role in a variety of consumer judgments including preference (Buchanan, Simmons, \& Bickart, 1999; Huber, Payne, \& Puto, 1982; Huber \& Puto, 1983; Simonson \& Tversky, 1992), product judgment (Janiszewski, Silk, \& Cooke, 2003) and comparative judgment (Manning, Miniard, Barone, \& Rose, 2001; Miniard, Rose, Manning, \& Barone, 1998; Rose et al., 1993; Shimp \& Dyer, 1978). Context is defined as a subjective context residing in working memory, represented by the set of stimuli accessible at judgment that is used to evaluate a target (Wedell, 1991). Recent context is represented by a set of recently viewed stimuli and is known to affect judgments following priming tasks (Wedell, 1991; Wedell, Parducci, $\&$ Geiselman, 1987). The recent context is likely to impact attribute judgments in the present studies since the experimental procedure sequentially exposes participants to brand representations in a learning task and later requires them to make attribute evaluations based on information retrieved from working memory. It is important to note that priming a linkage between brands (i.e., exposure to the brand alliance prime) further alters the content of the recent contextual input that is brought to judgment, as individuals may integrate the information of the two brands in memory.

Two types of context effects on individuals' judgments of a stimulus have been demonstrated in the marketing and social sciences literature: assimilation and contrast. Assimilation occurs when judgments of a target stimulus are displaced toward a contextual stimulus and refers to a positive correlation between the value assigned to the contextual stimulus and the value attributed to the target. On the other hand, contrast occurs when judgments of a stimulus are displaced away from the contextual stimulus and refers to a negative correlation between the values assigned to the contextual stimulus and target.

Two theoretical process models (Wedell, Hicklin, \& Smarandescu, 2007) that explain contrast and assimilation effects in judgment are relevant to the crosscategory brand alliance paradigm: priming models and situation-specific models. Priming models assume that the activation of a stimulus during priming affects judgments of other subsequent unrelated stimuli (Collins \& Loftus, 1975; Higgins, Rholes, \& Jones, 1977). Context effects in response to priming are attributed to a memory accessibility mechanism, suggesting that individuals use the recently activated context in a subsequent judgment. Priming models are useful in explaining contextual influences at exposure to cross-category alliance primes since individuals are visually primed with a brand linkage and later asked to make attribute judgments of both partner brands. It is important to make the distinction that the present research examines the effect of a brand linkage prime (i.e., a brand alliance ad exposure where the two linked brands provide an encoding context for each other) on subsequent ratings of brand attributes, while classic priming studies examine the effect of a single stimulus prime (e.g., exposure to a single concept, personality trait, or brand name) on ratings of an ambiguous target. It is proposed that the context activated at exposure to the brand alliance prime is likely to introduce an implicit comparison of the brands. The top two rows of Figure 1 compare the judgment processes occurring in classic or single stimulus (brand) priming, and brand alliance, or brand linkage priming. In classic priming, the prime (brand name) is presented incidentally and it is unlikely to be evaluated during its exposure. Later, when an ambiguous target brand is evaluated, the activated shared dimensions between the prime and the target are likely to shift judgment of the target toward the prime, inducing an assimilation effect. In a brand linkage prime, the target and the prime are simultaneously presented and their linkage is explicitly stated. Although brands are not explicitly judged during prime exposure, implicit comparisons may occur given enough processing motivation. If no comparisons occur, then effects at later judgment of the target will be similar to those of classic priming with assimilation being the likely effect. However, if implicit comparisons occur during brand alliance, or brand linkage prime encoding, these would emphasize differences 


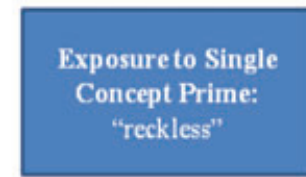

Prime Encoding

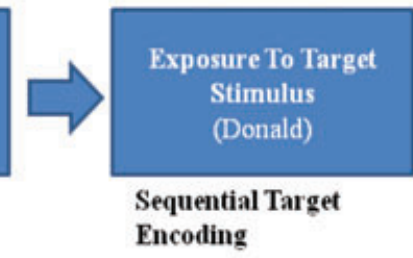

Brand Alliance Priming

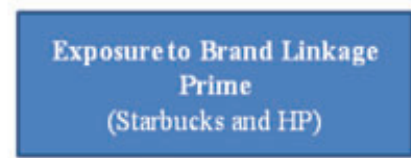

Simultaneous Target / Contextual Brand Encoding
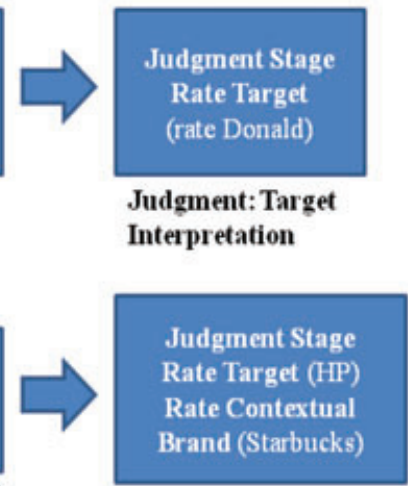

Judgment: Target /Contextual Brand Interpretation

Experimental Procedure Study 1
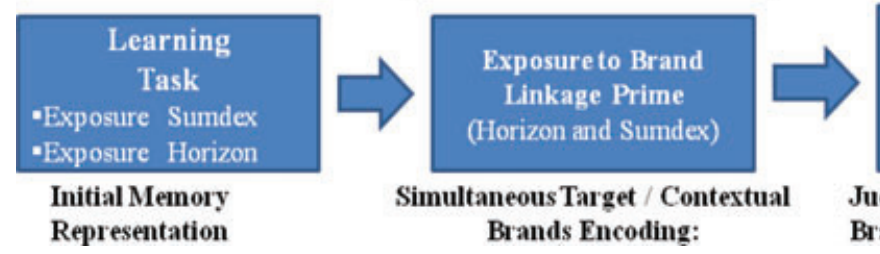

Judgment Stage

Rate Target (Horizon)

Rate Contextual

Brand (Sumdex)

Judgment: Target/ Contextual Brand Interpretation

Figure 1. Classic (single stimulus priming) versus brand linkage priming.

between the target and context and result in contrast effects.

Situation-specific models are also instrumental in explaining why both assimilation and contrast effects can be expected following exposure to cross-category alliance primes as a result of distinct aspects of the stimuli. Single-stimulus priming studies identified several factors that moderate the effect of the context on a target. These factors include the similarity between the target and the context (Herr, 1986), relevance of the context to the target (Wänke, Bless, \& Igou, 2001), extremity of the stimulus (Kenrick \& Gutierres, 1980; Kenrick, Gutierres, \& Goldberg, 1989; Schwarz \& Bless, 1992), and individual differences in processing motivation (Herr, Sherman, \& Fazio, 1983; Martin, 1986; Martin, Seta, \& Crelia, 1990; Mussweiler, 2003). The present research suggests that context effects on attribute judgment following exposure to a brand alliance prime are caused by priming a brand linkage. These effects are likely to be situation specific since they are moderated by the level of attribute knowledge, reflected in attribute alignability, attribute extremity, and individual differences in information processing, as measured by self-reported NFC measures.

\section{Moderators of Cross-Category Alliance Primes}

Attribute Knowledge. One distinctive feature of cross-category advertising alliances is that the partner brands differ with respect to their salient attributes and consumers often have incomplete information about brand attributes. When attributes differ between two or more brands being judged, the attributes are described as nonalignable and therefore require inference processes in order to make comparisons (Zhang \& Markman, 1998, 2001; Zhang, Kardes, \& Cronley, 2002). In a typical cross-category alliance product attribute information accessible in memory is likely to be nonalignable between brands and products. It is expected that conditions of low attribute knowledge (nonalignability) are more likely to facilitate attribute inferences than high attribute knowledge conditions, as shown by Zhang, Kardes, and Cronley (2002) and Kardes \& Sanbonmatsu (2003). Hence, in a low attribute knowledge situation individuals are more likely to use the contextual information of the brand partner as an anchor for judgments of a target, also consistent with findings from priming research suggesting that primes have larger effects on judgments of ambiguous than unambiguous targets (Higgins, Rholes, \& Jones, 1977). For example, brands such as Starbucks and Hewlett Packard belong to different product categories and do not share many attributes. Consumers may be familiar with Starbucks' strong community building orientation, but may not know anything about HP's attitude toward building communities. When exposed to an explicit linkage between the two brands, consumers may use information they have about Starbucks as an anchor for their judgments of HP's community orientation when they lack this information about HP. However, consumers may be less likely to use information they have about the 
brand partner as an anchor for judgments of a target when attribute information is available in memory for both the target and contextual brand (i.e., an alignable situation).

The alignability manipulation used in Study 1 was consistent with a procedure introduced by Zhang and Markman (2001) and served to create a parallel to brand alliances in the marketplace where individuals are presented with asymmetrical or missing information about partner brands. In a study involving preference judgment, Zhang and Markman (2001) described brands using both alignable and nonalignable attributes and investigated how individual motivation with processing affected the use of nonalignable features in choice. They found that high motivation with information processing enabled consumers to increase their use of nonalignable differences, whereas a lowmotivation condition leads to less focus on nonalignable attributes. However research in judgment and decision making also suggests that choice judgments are in fact significantly different from rating or evaluation judgments in their underlying cognitive processes, because in choice individuals place more weight on the differences between options than in rating or evaluation judgments (Hsee, 1996, 1998; Nowlis \& Simonson, 1997; Slovic \& MacPhillamy, 1974). Hence, it is suggested that the present priming task and the subsequent attribute rating judgments involve distinctly different processes than those observed in choice tasks. Individuals in the present studies are briefly primed with a brand linkage and are subsequently asked to rate both brands on target nonalignable attributes, thus they rely on information stored in memory to make judgments.

The Moderating Role of NFC. NFC is defined as a personal tendency to engage in and enjoy effortful cognitive activities (Cacioppo \& Petty, 1982). Individuals high in NFC show preference for cognitively effortful tasks without external motivation, whereas low NFCs avoid cognitively challenging tasks. Haugtvedt, Petty, \& Cacioppo (1992) suggest that low-NFC individuals are more likely to rely on cues and stereotypes in judgment, whereas high NFCs are more likely to consider all the relevant information at hand. Although NFC leads to increased thinking, it does not always lead to better judgments, as shown by Lerner and Tetlock (1999) in their review of the effects of accountability and depth of thought on individual susceptibility to bias.

There are two different views on how individual differences in NFC predict responses to classic (single stimulus) priming tasks. Priming effects require three basic steps (Petty \& Jarvis, 1996). First, exposure to a prime activates a construct in memory. Second, the activated construct must bias the interpretation of a target, and third, the individual must use the biased interpretation in judgment or behavior. Petty, DeMarree, Briñol, Horcajo, and Strathman (2008) suggest that at each of these steps high NFC would be more suscepti- ble to priming effects than low-NFC individuals. They suggest that since high-NFC individuals think about more topics, their constructs are better interconnected in memory (McGuire, 1981) and that their threshold for construct activation may be lower than for low-NFC individuals (Smith, Haugtvedt, \& Petty, 1994). Also, as high-NFC individuals tend to generate more thoughts in connection to a stimulus (Axsom, Yates, \& Chaiken, 1987), the content of these thoughts is more likely to be subject to the biasing influence of the prime. Finally, high NFCs are more likely to translate their thoughts into judgments than low-NFC individuals (Petty, Schumann, Richman, \& Strathman, 1993).

Other classic priming studies (Martin, 1986) support a different view that suggests that individuals who are less involved with a processing task are more susceptible to priming than individuals who are involved with the task, as they use less effort in processing and cannot separate the influence of the prime from their interpretation of the target. Petty \& Jarvis (1996) also show that high levels of NFC are likely to eliminate biases arising from overreliance on cognitive shortcuts. Martin's (1986) set/reset model proposes that individuals who are motivated with an information processing task attempt to assess their genuine impression of the target and are more likely to partial out the biasing information about the prime from their judgment of the target. Martin defines this partialing out of the information deemed irrelevant to the judgment as resetting and suggests that resetting leads to a contrast effect. Alternatively, Martin shows that individuals who are less motivated with the processing task are more likely to integrate the prime information in forming their impression about the target and show assimilation.

It is proposed that individual involvement with the processing task is captured in measures of information processing motivation such as NFC. Based on the theoretical implications of Martin's set/reset model (1986), it is predicted that individual differences in NFC would moderate target attribute inferences following exposure to a brand linkage prime. It is expected that lowNFC individuals who use less effort in processing task information are more likely to be impacted by exposure to a brand alliance prime than high-NFC individuals. Low-NFC individuals will incorporate the contextual information provided by the brand partner in their judgment of a target. On the other hand, highNFC individuals who exert more effort in processing and analyzing task information are less likely to be impacted by the brand linkage prime and will partial out the bias introduced by the brand alliance prime from their judgments of the target.

\section{STUDY 1}

The goal of Study 1 was to examine the effects of exposure to a cross-category brand alliance prime on target attributes in different conditions of attribute knowledge (i.e., when individuals have information about 
target attributes of both brands and brand attributes are alignable, as opposed to a situation when individuals have incomplete information about target attributes of both brands and attributes are nonalignable) and to test for the moderating effect of NFC. It is proposed that conditions of low attribute knowledge (i.e., when brands are represented with nonalignable attributes) are more conducive to inferences and more likely to facilitate the use of contextual information in judgment of a target than conditions of high attribute knowledge (i.e., when brands are represented with alignable attributes), in line with research by Kardes \& Sanbonmatsu (2003) and Zhang, Kardes, and Cronley (2002). In addition, consistent with findings from the priming literature it is expected that extreme attribute information provided by the brand partner is more likely to impact judgment of a target than less extreme attribute information (Kenrick \& Gutierres, 1980; Kenrick, Gutierres, \& Goldberg, 1989; Schwarz \& Bless, 1992). It is also proposed that low-NFC individuals who are less motivated with a processing task would be less likely to use processing resources with the goal of making accurate judgments of the target. Thus, when presented with a brand alliance prime these individuals would be more likely to incorporate irrelevant attribute information provided by the brand partner (i.e., nonalignable attribute information) in their judgments of a target, showing evidence of assimilation. On the other hand, when high-NFC individuals who are more engaged with a processing task are primed with a cross-category alliance they are more likely to partial out the irrelevant, nonalignable attribute information provided by the brand partner. It is expected that high-NFC individuals will either show no bias, or overcorrect their target brand judgments in the direction opposite to the brand partner showing evidence of contrast. The following four hypotheses are proposed:

H1: Exposure to a brand alliance prime will impact target brand attribute judgments in the low attribute knowledge (nonalignable attribute) condition, but not in a high attribute knowledge (alignable attribute) condition.

H2: Extreme attribute information provided about a brand partner is more likely to affect judgment of a target than less extreme attribute information.

H3: In a low knowledge (nonalignable attribute) condition, low-NFC individuals exposed to a brand alliance will assimilate their ratings of target brand attributes in the direction of the brand partner.
H4: In a low knowledge (nonalignable attribute) condition, high-NFC individuals exposed to a brand alliance will show no effect of the prime, or will contrast their ratings of target brand attributes in a direction opposite to the brand partner.

Participants and Design. Two hundred and thirty students participated in this study for course credit in full accordance with the university guidelines for the protection of human subjects. The study design was a 2 (knowledge: alignable vs. nonalignable target attributes $) \times 2$ (alliance prime: prime present vs. prime absent) $\times 2$ (high vs. low NFC, based on a median split) between-participants design. Students were randomly assigned to one of the four experimental conditions (i.e., knowledge $\times$ prime) and responded to a measure of NFC (Cacioppo, Petty, \& Kao, 1984).

Stimulus and Method. Upon entering the lab, participants were informed that the purpose of the study was to assess how consumers form perceptions of relatively new brands. The study was conducted on computers using Eprime Pstnet software. As part of a learning task participants were exposed to two hypothetical brands, Horizon and Sumdex, which were described through user star ratings and product pictures. The brands were presented sequentially and in random order. Horizon brand was identified with a picture of inline skates and Sumdex was identified with picture of a portable music player. The two product categories, inline skates and music player, were selected as a result of a pretest that showed that participants associated them with a common goal, outdoor leisure. Participants were sequentially exposed to star ratings for each brand provided by three different online users; in total participants saw six user ratings. Each computer screen featured an identical picture of the product and a user star rating on four attributes; the brand picture was placed on the left side of the screen, whereas the star ratings were presented on the right side of the screen. User star ratings were provided on four attributes selected from different subdimensions of Aaker's (1984) brand personality scale: rugged, down-to earth, reliable, and sophisticated. The user ratings were given in multiples of half star. Across the three user ratings the brands were equivalent in their mean star ratings on three of the four featured attributes: rugged, down-to-earth, and sophisticated $(M=3 ; M=1.83 ; M=1.33)$. The two attribute knowledge conditions differed with respect to the information provided on the fourth target attribute. In the high attribute knowledge (i.e., alignable attribute) condition, individuals were presented with user ratings on the fourth attribute, reliability, for both brands (Horizon, $M=2.5$ vs. Sumdex, $M=4.5$ ). In the low knowledge (i.e., nonalignable) condition individuals received nonalignable information on the fourth attribute. Sumdex received user ratings on reliability $(M=4.5)$, while no 
Table 1. Study 1 Learning Task: Average Star Ratings across Three Users.

\begin{tabular}{|c|c|c|c|c|c|c|c|}
\hline \multicolumn{4}{|c|}{ Low Knowledge (Nonalignable) } & \multicolumn{4}{|c|}{ High Knowledge (Alignable) } \\
\hline Sumdex & & Horizon & & Sumdex & & Horizon & \\
\hline Rugged & 3.00 & Rugged & 3.00 & Rugged & 3.00 & Rugged & 3.00 \\
\hline Down to earth & 1.83 & Down to earth & 1.83 & Down to earth & 1.83 & Down to earth & 1.83 \\
\hline Sophisticated & 1.33 & Sophisticated & 1.33 & Sophisticated & 1.33 & Sophisticated & 1.33 \\
\hline Reliable & 4.50 & Exciting & 2.50 & Reliable & 4.50 & Reliable & 2.50 \\
\hline
\end{tabular}

information was provided about Horizon's reliability. Instead, Horizon was rated on excitement $(M=2.5)$. For experimental control, we manipulated the extremity of the ratings for the target attribute, reliability. The contextual brand, Sumdex, received an extreme rating on this attribute, while the target brand, Horizon, received an average rating on all attributes (see Table 1). ${ }^{1}$ Consistent with findings in the priming literature, it was expected that the attribute receiving an extreme user rating would be more salient and provide a stronger context for judgments of the target brand, Horizon. Thus, it was predicted that Sumdex's more extreme reliability rating would be likely to influence ratings of Horizon's reliability (a brand described with moderate, thus less salient ratings on all attributes), but not vice versa. Horizon's user rating on the excitement would be less salient, being within the range of other attribute star ratings, and thus, would not be expected to impact judgment of Sumdex's excitement. It was also expected that the effect of the brand alliance exposure on the target attribute reliability would be stronger in the low attribute knowledge condition when individuals did not receive user rating information on this attribute for both brands and they would be more likely to engage in inference processes. Hence, the effect of the brand alliance prime was expected to be diminished or null when individual had complete user information for both brands on the target attribute.

After exposure to the learning task, all individuals completed an unrelated distraction task ${ }^{2}$ that lasted about 10 minutes and responded to an 18-item NFC scale (Cacioppo, Petty, \& Kao, 1984). Participants in the experimental group were next exposed to examples of ads from a fictitious advertising campaign featuring a brand alliance between Horizon and Sumdex. The brand alliance ad exposure served as a brand linkage prime; the ad prime was presented four times ${ }^{3}$ for

1 This attribute extremity manipulation provides ecological validity to our experiment as consumers are likely to have multiattribute representations of brands in memory, and often a brand with moderate ratings on a target attribute would choose to pair up with a brand partner featuring a more extreme positive attribute rating.

2 The distraction task required participants to rate their willingness to pay for a variety of products purchased online, featuring different face value plus shipping price combinations.

3 The brand alliance prime was presented four times for the purpose of enhancing the brand alliance prime manipulation. Real-world advertisements are far more attention getting and more memorable than the brand alliance stimulus used in this study as they are loud, striking, use catchy phrases, vivid imagery, music, or humor. For experimental control purposes the present ad was not embellished three seconds each. Each ad included a picture of the two products and featured a tagline emphasizing the linkage between the two brands. The taglines did not feature any brand attributes since the purpose of the study was to test whether priming the mere linkage between the two brands would change attribute perceptions of the brands in comparison to a condition where the brand alliance prime is absent. To enhance the experimental realism, four different taglines were used and all subjects in the experimental group were exposed to all four taglines in random order: "Horizon and Sumdex: Better Together," "Horizon and Sumdex: We Teamed Up for You," "Horizon and Sumdex: Enhance Your Experience," and "Horizon and Sumdex: It Just Gets Better" (Figure 2). After exposure to the brand alliance ads, participants in the experimental group rated their perceptions of the two focal attributes, reliability and excitement, using 9-point scales, anchored with not at all and very much so. The focal attributes were embedded among six other filler attributes in the questionnaire and the order of the attributes was randomized by the computer program. Participants in the control group were exposed to the same learning task in which they learned about the two brands sequentially and in random order, completed the same distraction task, evaluated the two target brands on the same eight attributes, also randomized, and completed the NFC scale.

It is important to note that the priming procedure used in Study 1 differs from Martin's (1986) classic priming procedure, since his study involved only two judgment stages: (1) a first stage when individuals were exposed to a single concept prime and (2) a stage when individuals made judgments of an ambiguous target, and in doing so they incorporated the recent context provided by the prime in judgment. In comparison, the present procedure involves three judgment stages: (1) a learning task where individuals learn and store initial attribute information about the partner brands in memory (this stage creates a memory representation baseline that already exists for brands in the marketplace), (2) a priming stage when individuals are exposed to a brand alliance prime and they encode the brand linkage, and (3) a brand judgment stage when participants rate the attributes of both brands. The key difference between Martin's (1986) procedure and the present study is that individuals are presented with a

in ways similar to advertisements in the marketplace since the purpose of the study was to demonstrate that mere exposure to a brand linkage leads to attribute inferences. 


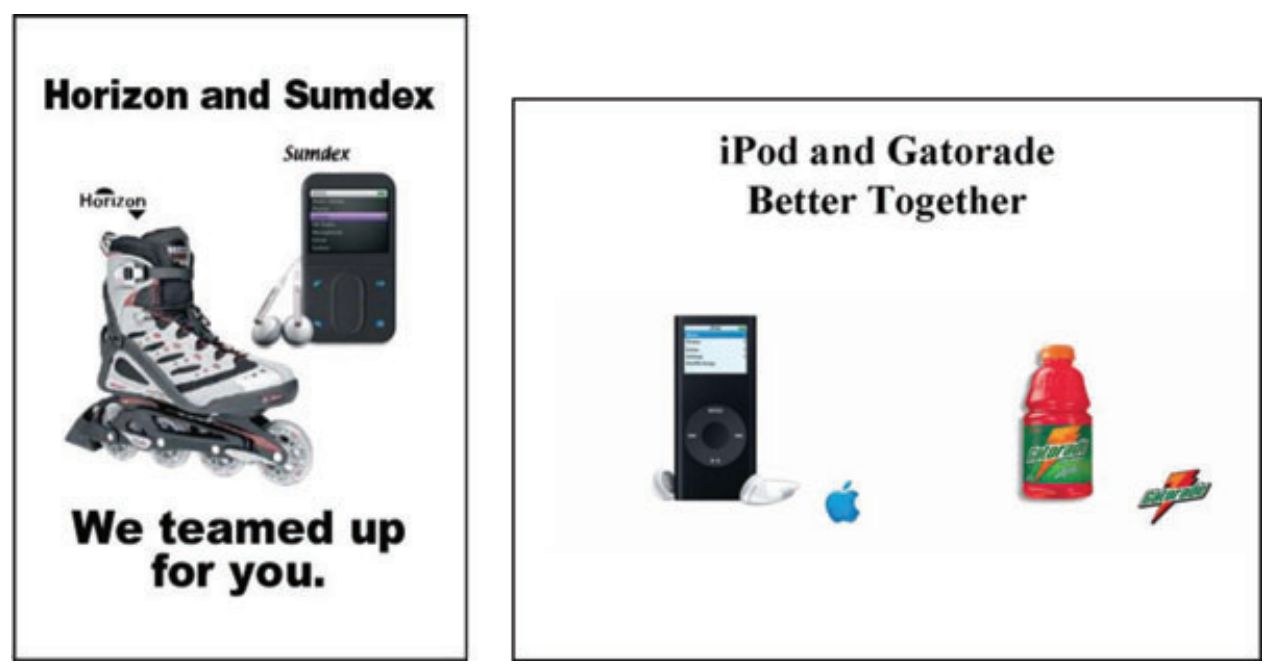

Figure 2. Examples of brand alliance ads used in Studies 1 and 2.

brand linkage prime (i.e., brand alliance as opposed to a single stimulus (concept) prime. Therefore, in the experimental condition, the recent context that is likely to affect the interpretation of the target is modified by the exposure to the brand linkage in comparison to a control group where brand information is encoded in isolation during the learning task.

\section{Results}

A two-way ANOVA using Horizon's reliability ratings as a dependent variable indicates a marginally significant main effect of attribute alignability $\left(F_{(1,222)}=3.56\right.$, $p=0.06$ ), a significant two-way interaction between the presence of the alliance and $\operatorname{NFC}\left(F_{(1,222)}=5.05, p<\right.$ 0.05 ), and a significant three-way interaction between the presence of the alliance, attribute alignability and $\mathrm{NFC}^{4}\left(F_{(1,222)}=6.15, p<0.05\right)$. Given the presence of the three-way interaction, the main effect and the twoway interaction are not discussed as they do not provide useful information.

Examining the relevant paired contrasts in the high attribute knowledge alignable condition (i.e., when user ratings on reliability are presented for both brands) shows that neither high- or low-NFC individuals changed their ratings of Horizon's reliability following exposure to a brand alliance prime in comparison to high- or low-NFC individuals in the control group

4 Reliability scores were not normally distributed, in violation of the assumptions of regression analysis. Shapiro-Wilk normality tests were performed overall, within the two alignability conditions, and within the two alliance conditions. All three Shapiro-Wilk tests were significant $(p<0.001)$, indicating deviations from normal distributions. A median split was done and NFC was treated as a dichotomous variable in line with research that looked at NFC as an independent variable (Coutinho, Wiemer-Hastings, Skowronski, \& Britt, 2005; Giese \& Sojka, 1998; Haugvedt \& Petty, 1989; Haugvedt, Petty, Cacioppo, \& Steidley, 1988; Peck \& Loken, 2004; Petty et al., 1993). $\left(t_{\text {High }(222)}=0.83, p>0.1 ; t_{\text {Low }(222)}=0.67, p>0.1\right)$. However, in conditions of low attribute knowledge, when information about Horizon's reliability was nonalignable, low-NFC individuals exposed to a brand alliance used the contextual information about the brand ally in judgment and assimilated their judgments of Horizon reliability $\left(t_{\text {Low }(222)}=2.01, p<0.05\right)$ in the direction of the more extreme brand partner. Thus, they rated Horizon higher on reliability $\left(M_{\text {Low-Alliance }}=6.95\right)$ after exposure to a brand alliance prime than low-NFC individuals in the control group $\left(M_{\text {Low-Control }}=6.14\right)$. Also, highNFC individuals exposed to nonalignable information about Horizon's reliability contrasted their judgments of in a direction opposite to the context provided by the brand partner $\left(t_{\operatorname{High}(222)}=-2.43, p<0.05\right)$; they rated Horizon lower on reliability when they were exposed to a brand alliance $\left(M_{\text {High-Alliance }}=6.08\right)$ than high-NFC individuals in the control group ( $M_{\text {High-Control }}$ $=7.29$ ). Means and standard deviations are presented in Table 1. As expected, exposure to the brand alliance prime did not affect individual ratings of Sumdex's excitement in either of the attribute knowledge conditions (high: $F_{(1,222)}=0.012, p>0.1$; low: $F_{(1,94)}=0.5$, $p>0.1$ ).

The effects above also replicate when the analysis is repeated using the difference between the reliability ratings of Sumdex and Horizon as a dependent variable $\left(F_{(1,222)}=5.76, p<0.05\right)$. This measure is informative as it captures movement in both brands on this target attribute. Thus, if individuals assimilate the two brands, they would view them as more similar on the reliability dimension and the distance between brands would decrease after exposure to the brand alliance prime in comparison to individuals who are not exposed to a brand alliance. However, when brands are contrasted they would be perceived as more dissimilar on reliability following brand alliance exposure and the distance between the brands would increase in comparison to the control group. In a high attribute knowledge condition (i.e., alignable attributes), the difference in 
Table 2. Study 1: Reliability Ratings Horizon Difference Scores (Sumdex-Horizon) on Reliability Means and Standard Deviations.

\begin{tabular}{|c|c|c|c|c|c|}
\hline & & \multicolumn{2}{|c|}{ High Knowledge/Alignable } & \multicolumn{2}{|c|}{ Low Knowledge/Nonalignable } \\
\hline & & Alliance & Control & Alliance & Control \\
\hline \multirow[t]{2}{*}{ Horizon reliability } & Low NFC & $6.08(1.59)$ & $6.42(1.29)$ & $6.95(1.00)$ & $6.14(1.61)$ \\
\hline & High NFC & $6.06(1.98)$ & $6.30(1.58)$ & $6.08(1.26)$ & $7.29(1.07)$ \\
\hline \multirow[t]{2}{*}{ Difference reliability } & Low NFC & $1.79(2.00)$ & $1.35(1.70)$ & $0.15(0.81)$ & $1.14(1.98)$ \\
\hline & High NFC & $1.47(2.73)$ & $1.40(1.95)$ & $1.62(1.75)$ & $0.36(1.28)$ \\
\hline
\end{tabular}

Note: Standard deviations are in parentheses.

reliability scores between the two brands did not significantly change for individuals exposed to a brand alliance in comparison to individuals in the control group for either low- or high-NFC individuals $\left(t_{\text {Low }(222)}\right.$ $\left.=0.47, p>0.1 ; t_{\text {High }(222)}=0.44, p>0.1\right)$. However, in a low attribute knowledge condition (i.e., nonalignable attributes) the difference in the reliability ratings between the two brands decreased when low-NFC individuals were exposed to a brand alliance prime, in support of an assimilation effect. This group perceived the brands as more similar when they were exposed to a brand alliance prime in comparison to a control condition $\left(t_{\text {Low }(222)}=1.94, p=0.05\right)$. In comparison, highNFC individuals perceived the distance between the brands to increase (i.e., brands were seen as more dissimilar) when they were exposed to a brand alliance prime in comparison to high-NFC individuals in the control group $\left(t_{\mathrm{High}(222)}=-2.10, p<0.05\right)$, a contrast effect. Table 2 summarizes the means and standard deviations.

\section{Discussion}

Study 1 examined how priming individuals with a cross-category brand alliance prime influences judgments of a target brand attribute in different conditions of attribute knowledge and directly compared scenarios when individuals were provided with alignable versus nonalignable attribute information. This study shows that higher levels of attribute knowledge inhibit individuals use of contextual information in their judgments of a target. When individuals have access to complete (i.e., alignable) information for both brands on a target attribute they are less likely to use the contextual information of the brand partner in their subsequent attribute evaluations, so the effect of the prime was eliminated in this condition.

However, in conditions of low attribute knowledge (i.e., nonalignable attribute information) that are typical of real-world cross-category alliances individual differences in processing motivation as reflected in NFC moderate the extent to which individuals use contextual information in judgment. High-NFC individuals who were more motivated to correct for the bias introduced by the brand alliance partner, Sumdex, partialed out the influence of the brand partner form their judgment of the target, and in doing so they overadjusted their evaluations of Horizon's reliability in a direction opposite to the brand partner. In comparison, low-NFC individuals were less likely to view the information provided on Sumdex's reliability as a source of bias for their judgment of Horizon reliability and assimilated their judgments of Horizon in the direction of the brand partner.

In conclusion, Study 1 shows that the effect of a brand alliance prime can be eliminated when individuals have complete information about attributes of both brands. A possible explanation may be that when individuals have well-established memory brand schemas they are more likely to use their existing schemas in judgment, and less likely to rely on, and integrate contextual information in judgment. However, one may argue that the elimination of the effects in the high knowledge condition may be due to an excessive manipulation since individuals in this condition were given complete user ratings for the attributes of both brands, including the target attribute, reliability. Since this was the only information available to participants in this study (outside the brand linkage prime), it is plausible that they were less likely to use the contextual information provided by the brand alliance in their brand judgments and directly retrieved the attribute rating information stored in working memory. Although the attribute knowledge manipulation in this study allowed for experimental control, the inference processes used by individuals when exposed to alliances between brands with well-defined memory schemas may differ. We designed Study 2 to test for the effects of a brand alliance prime on brands with distinct and well-established memory schemas.

\section{STUDY 2}

Following a pretest that measured familiarity with brands, two brands were selected for this new experiment: Gatorade soft drinks and Apple iPod players. Both brands were perceived as equally familiar and both were frequently used by the undergraduate sample. The goal of the pretest was to identify product categories participants were equally familiar with, in order to avoid having individual differences in product category expertise moderate the results. The pretest identified two target dimensions that were perceived to be equally relevant for these brands: "appeals to the young" and an evaluative attribute, "high quality." In the pretest, Apple was rated significantly higher than 
Gatorade on both "appeals to the young" and "high quality." The pretest identified other two dimensions that were viewed as equally relevant for both brands, "convenient" and "outdoorsy", however the brands were not perceived as significantly different on these dimensions. In line with Study 1, it was expected that exposure to brand alliance prime would have a larger impact on attributes with extreme ratings, perceived to be significantly different for the brands. Since Apple received a higher, more extreme rating on both "high quality" and "appeals to the young," it was expected to provide a context for the attribute ratings of Gatorade on these dimensions. However, since this experiment was concerned with exploring the effect of a brand alliance prime on brands with complex memory representations, the effects of the alliance prime were also examined on the ratings of the contextual brand, Apple, as it was also plausible that less positive memory representations of Gatorade's attributes may influence Apple ratings, although this effect was expected to be weaker. The following hypotheses were proposed:

H1: Extreme attribute information provided about a brand partner is more likely to affect judgment of a target than less extreme attribute information. Apple attribute ratings are more likely to affect Gatorade ratings than vice versa.

H2: Low-NFC individuals exposed to a brand alliance will assimilate their ratings of target brand attributes (Gatorade) in the direction of the brand partner (Apple).

H3: High-NFC individuals exposed to a brand alliance will either show no effect of the brand alliance prime, or will contrast their target brand attribute ratings (Gatorade) in a direction opposite to the brand partner.

\section{Participants and Method}

Ninety-seven undergraduate students from a public university volunteered to participate in this two-part 2 (alliance prime: absent/present) $\times 2$ (NFC: low/high based on a median split) mixed design study for course credit. Study 2 was designed as a two-session experiment in order to control for large betweenindividual differences in attribute perceptions of established brands, which if unaccounted for, could make the effect of the brand alliance exposure difficult to detect. To account for the individual variability in brand perception, the participants' perceptions of the target attributes were measured in both sessions of the exper- iment. The second part of the experiment was scheduled a week later in order to prevent participants from retrieving their initial brand evaluations from memory.

In session one, participants were informed that the purpose of the study was to examine their perceptions of brand personality attributes for several brands. The procedure sequentially exposed individuals to pictures of two target brands, Gatorade soft drinks and Apple iPod players, embedded among four other filler brands and asked them to rate all brands on the two target and two nontarget attributes. After evaluating all six brands on all four attributes, participants responded to the 18-item NFC scale. Session two took place a week later, and participants were randomly assigned to either a control condition in which they were presented with the same experimental stimulus as in part one that required them to evaluate a series of brands, or to a brand alliance prime condition in which they were exposed to a series of brand alliance ads. Participants in the brand alliance condition were informed that researchers were interested in their perceptions of brand alliance ads. Next they were exposed to four brand alliance ads featuring the same taglines as in study one except that the target alliance ads in this study emphasized the linkage between Gatorade and Apple. The four target brand alliance ads were alternated with eight other brand alliance ads featuring two other filler brand pairs (Figure 2). Following exposure to the brand alliance ads, participants were asked to rate the two target brands on the two target and two nontarget attributes. All participants rated all six brands on all four attributes. Brand order and attribute order within brand were randomized.

\section{Results}

Five participants were excluded from the analysis because they did not complete both parts of the experiment, which reduced the final participant sample size to 92 . The variables of interest in this study were ratings of Gatorade and Apple on "appeals to the young" and "high quality," as the pretest showed the brands as significantly different on these dimensions. A two-way ANCOVA using the presence of the brand alliance and NFC as independent variables, Gatorade's Phase 2 rating on "appeals to the young" as a dependent variable and Gatorade's Phase 1 rating on "appeals to the young" as a covariate resulted in a main effect of the presence of the brand alliance $\left(F_{1,87}=10.71, p<0.01\right)$. Individuals exposed to a brand alliance prime between Gatorade and Apple rated Gatorade higher on "appeals to the young" than individuals in the control group $\left(F_{1,89}=\right.$ $10.74, p<0.01$ ); the corresponding means were 7.2 and 6.21. This indicates that ratings of Gatorade on this attribute improved after exposure to the brand alliance prime, consistent with an assimilation effect, in comparison to a control group when participants were not exposed to a brand linkage prime. Next, the 
Table 3. Study 2: Ratings of "Appeal to the Young" and "High Quality" for Both Brands as a Function of NFC and Alliance Condition Means and Standard Deviations.

\begin{tabular}{|c|c|c|c|c|c|}
\hline & & \multicolumn{2}{|c|}{ Low NFC } & \multicolumn{2}{|c|}{ High NFC } \\
\hline & & Alliance & Control & Alliance & Control \\
\hline \multirow[t]{3}{*}{ Appeal } & Gatorade & $6.83(1.11)$ & $6.09(1.98)$ & $6.83(1.24)$ & $6.27(1.64)$ \\
\hline & Apple & $7.78(1.20)$ & $7.22(1.41)$ & $8.46(0.66)$ & $7.55(1.26)$ \\
\hline & Difference $(A-G)$ & $0.96(1.07)$ & $1.13(1.66)$ & $0.83(1.20)$ & $1.27(1.55)$ \\
\hline \multirow[t]{3}{*}{ High quality } & Gatorade & $6.30(1.74)$ & $6.26(1.96)$ & $6.50(1.22)$ & $5.90(1.93)$ \\
\hline & Apple & $7.09(1.59)$ & $8.04(0.88)$ & $8.17(0.82)$ & $7.27(1.58)$ \\
\hline & Difference $(\mathrm{A}-\mathrm{G})$ & $0.78(2.04)$ & $1.78(1.81)$ & $1.67(1.40)$ & $1.36(1.64)$ \\
\hline
\end{tabular}

Note: Standard deviations are in parentheses.

effect of the brand alliance on Apple's ratings was examined. A two-way ANCOVA using the presence of the brand alliance prime and NFC as independent variables, Apple's Phase 2 rating on "appeals to the young" as a dependent variable and Apple's Phase 1 rating on "appeals to the young" as a covariate also resulted in a main effect of the brand alliance $\left(F_{1,89}=10.55\right.$, $p<0.01$ ). Inspecting the relevant means indicates that individuals who were exposed to a brand alliance prime also rated Apple higher on "appeals to the young" than individuals in the control group, in support for a contrast effect; corresponding means for the control and alliance groups were 8.13 and 7.37. Next, a two-way ANCOVA using the presence of the brand alliance and NFC as independent variables, Apple's Phase 2 rating on "high quality" as a dependent variable and Apple's Phase 1 rating on "high quality" as a covariate, resulted in a significant interaction between condition and NFC $\left(F_{1,87}=6.52, p=0.01\right)$. Examining the relevant paired contrasts shows that high-NFC individuals enhanced their ratings of Apple's "high quality" when exposed to a brand alliance prime in comparison to individuals in the no prime control condition $\left(F_{1,43}=3.72\right.$, $p=0.06)$, although this effect was only marginally significant; the corresponding means are 7.88 and 7.33 , respectively. In comparison, low-NFC individuals exposed to a brand alliance prime did not differ from individuals in the control group in their ratings of "high quality." Also, priming the linkage with Apple had no significant effects on Gatorade's "high quality" ratings. No significant effects were observed on the other nonsalient attributes, "convenient" and "outdoorsy." The relevant means and standard deviations are included in Table 3.

\section{Discussion}

Results from Study 2 broaden the understanding of the inference processes that may occur at exposure to a brand alliance prime in a more ecologically valid context when individuals have well-formed memory representations of brands. Data indicate that exposure to a brand alliance in these situations is likely to benefit both brands and result in strengthened attribute ratings. For example, attribute ratings of a brand per- ceived as moderate in attribute values, Gatorade, tend to move upward in the direction of the more extreme, thus salient brand partner (Apple), indicating an assimilation effect. Importantly, ratings of the more extreme brand Apple were not assimilated in the direction of the weaker brand partner. On the contrary, attribute ratings of the more extreme brand showed further improvement following linkage with a moderate brand, although this effect was only marginally significant.

Data from this study also indicate that when individuals have well established memory schemas for brands, different attributes may be differently affected by the brand linkage prime. For example, NFC did not moderate the effect of the brand alliance prime on "appeals to the young" ratings; only a main effect was identified on this attribute. It appears that exposure to the brand linkage prime helped perceptions of both brands on this attribute as if this attribute created a synergy between the brands. Indeed, the student participants did report using the two target brands Apple iPod and Gatorade drinks for a common goal, exercising. However, NFC moderated the effect of the alliance prime on ratings of Apple's "high quality," an evaluative attribute similar to the "reliability" attribute used in Study 1. Data from Study 2 show that the less prominent brand, Gatorade, was less likely to benefit from the exposure to the brand alliance prime on ratings of "high quality." This result parallels the effect observed in Study 1 in the high knowledge condition and suggests that when individuals have a good knowledge about a brand (in this case a mediocre memory representation of Gatorade's quality) they are less likely to use the contextual information of the brand partner to adjust their existing attribute evaluations. Exposure to a brand alliance seemed to have strengthened Apple's "high quality" ratings for high-NFC individuals, although this effect did not achieve significance. One plausible explanation for these effects could be that in conditions of high attribute knowledge (high quality is an attribute central to the Apple brand) high-NFC individuals reacted to the perceived bias introduced by the linkage between the high quality Apple brand and the quality inferior partner Gatorade and overcorrected their judgments of Apple in a direction opposite to its inferior brand partner. 


\section{GENERAL DISCUSSION AND IMPLICATIONS}

The present research examined the moderating effect of attribute knowledge on the inferences made by individuals at exposure to cross-category brand alliance primes. Data show that the level of attribute knowledge individuals have about brands moderates the effect of the brand alliance prime on brand attribute judgments and interacts with individual differences in processing motivation such as NFC. Data provide support for the expectation that a more ambiguous information context, a situation characteristic of most cross-category brand alliances, encourages inference processes. Also, in conditions of low attribute knowledge, individual differences in processing motivation as reflected in NFC measures result in different attribute inferences at exposure to a brand alliance prime. This research shows that low-NFC individuals tend to integrate the contextual information introduced by the brand partner in judgment, whereas high-NFC individuals view the contextual information provided by the brand ally as irrelevant to their judgment and either partial out, or overcorrect their target attribute judgments in a direction opposite to the brand ally. With respect to the timing of the inference process, in Martin's (1986) and Martin, Seta, and Crelia's (1990) classic priming studies, the effect of the prime on judgment is likely to take place at judgment stage, as this is the stage where the target is first considered in the light of the prime. In the current priming paradigm, the effect of the brand association prime may take place either at brand alliance prime encoding, when individuals are first exposed to the target in the light of the prime and they encode the information about each brand in the context of the other, or at attribute judgment (interpretation) stage. Further research is necessary to explain the timing of these inference processes.

This research presents an important contribution for the marketing field by examining the effect of crosscategory brand alliance primes on brand attributes in the context of familiar brands with well-established memory schemas. In this situation of high ecological validity, it was shown that when a target attribute is relevant to both partner brands, brands might experience synergies following exposure to a brand alliance prime and mutually benefit from improved ratings. Hence, individuals tend to assimilate their judgments of a moderate, less salient brand in the direction of the more extreme, stronger brand, and also enhance their ratings of the later. Another important finding that is that when a target attribute has stronger associations with one brand, as it is the case with Apple's high quality, individuals are less likely to anchor their judgment on the contextual information provided by the inferior brand.

The present research findings present important implications for marketers contemplating cross-category advertising alliance strategies between partner brands that share little or no attribute overlap. In addition, this research may be useful in informing advertising channel selection decisions. For example, advertising channels associated with low levels of information processing involvement (e.g., TV programming) would be more favorable venues for these brand alliance strategies than channels associated with high levels of processing involvement (e.g., print media). The present findings would suggest that individuals exposed to a brand alliance ad featured on TV would be more likely to make inferences that would parallel those of lowNFC individuals, and assimilate their judgments in the direction of the brand ally. In comparison, some forms of print media (e.g., Scientific American) are more likely to attract individuals who are motivated with information processing and who would show inference processes similar to those shown by high-NFC individuals. Although this research has not directly tested for advertising channel effects, it is plausible to suggest that cross-category brand alliances advertised in print publications appealing to high-NFC individuals may be more likely to work against brands using this form of advertising, as these individuals tend to contrast their judgments of a moderate target in a direction opposite to a brand ally, as opposed to assimilating. This is an important finding for brand managers, as several such alliances are placed in print publications targeting high-NFC individuals.

\section{LIMITATIONS AND FUTURE RESEARCH DIRECTIONS}

Across two studies it was found that low- and high-NFC individuals respond differently to a brand linkage in a cross-category advertising alliance as the result of different inferences. It was demonstrated that even in a highly controlled experimental environment there are several variables that come into play to affect individual attribute judgments at exposure to a brand alliance prime. Some of the variables identified by this research include attribute knowledge, attribute extremity, and individual differences in NFC. Other factors that may impact brand inferences at exposure to a cross-category alliance are product category fit, processing goals (e.g., generalization vs. discrimination goals), attribute relevance to the goal of the alliance, etc. Future research is needed to explore these other factors.

It is important to recognize some of the limitations of this research. One limitation of Study 1 is that due to experimental control considerations, the design was constrained to focus on the effects of the alliance on one target attribute that was made salient in the stimulus. It was shown that attributes with extreme ratings are more salient in judgment than attributes with moderate ratings, and that attribute salience may turn on and off the effect of the brand alliance. This design is ecologically valid since most alliances in the marketplace are formed between a stronger, more prominent 
contextual brand that is likely to provide a context for a less prominent target brand. Nonetheless, there may be advertising situations where both brands in a brand alliance are equally salient and both have extreme memory representations.

Second, this research did not investigate the theories of bias held by individuals when they are exposed to cross-category brand alliances. A logical extension of this research would examine these theories, as these are likely to influence the direction and the magnitude of the subsequent correction processes. Petty et al. (2008) suggest that characteristics of the prime itself can lead to different inferences under varying levels of NFC (see also Lombardi, Higgins, \& Bargh, 1987). Future studies would manipulate the salience of the brand linkage prime and investigate the effects of the prime on high- and low-NFC individuals' ratings of brand attributes. Third, it would fruitful to examine the effects of brand alliance primes on individual brands over time. Research by Haugtvedt et al. (1988) shows that although low- and high-NFC individuals may express similar attitudes right after exposure to an ad, their attitudes may change in different ways with passage of time. The present studies also show that high and low NFCs account differently for brand linkage information provided by the brand alliance prime. Understanding this issue may allow marketers to make better predictions about what leads to strong attribute associations over time. Finally, while the current research was concerned with the effect of brand alliance exposure on perceptions of brand attributes, it would be useful to ascertain whether or not brand alliance advertising offers persuasion advantages. Future research could then compare the relative persuasiveness of brand alliance advertising, comparative, and noncomparative advertising using brand attitude measures. An interesting direction for future research may be to look at the degree to which cross-category advertising alliances allow marketers to avoid counterargumentation typically elicited by more explicit persuasion attempts such as comparative advertising. Open-ended cognitive response measures may be used to reveal the different types of thoughts elicited by these ad formats, relative to explicit comparative or noncomparative formats.

\section{REFERENCES}

Aaker, J. (1997). Dimensions of brand personality. Journal of Marketing Research, 34, 347-356.

Aaker, D. A., \& Keller, K. L. (1990). Consumer evaluations of brand extensions. Journal of Marketing, 54, 27-41.

Axsom, D., Yates, S., \& Chaiken, S. (1987). Audience response as a heuristic cue in persuasion. Journal of Personality and Social Psychology, 53, 30-40.

Bambauer-Sachse, S., Hüttl, V., \& Gierl, H. (2011). Can advertising elements improve consumer evaluations of brand extensions with a moderate or low fit? Psychology \& Marketing, 28, 205-218.
Buchanan, L., Simmons, C. J., \& Bickart, B. A. (1999). Brand equity dilution: Retailer display and context brand effects. Journal of Marketing Research, 36, 345-355.

Cacioppo, J. T., \& Petty, R. E. (1982). The need for cognition. Journal of Personality and Social Psychology, 42, 116131.

Cacioppo, J. T., Petty, R. E., \& Kao, C. F. (1984). The efficient assessment of need for cognition. Journal of Personality Assessment, 48, 306-307.

Collins, A. M., \& Loftus, E. F. (1975). Spreading-activation theory of semantic processing. Psychological Review, 82, 407-428.

Coutinho, S., Wiemer-Hastings, K., Skowronski, J., \& Britt, A. (2005). Metacognition, need for cognition and use of explanations during ongoing learning and problem solving. Learning and Individual Differences, 4, 321337.

Droge, C., \& Darmon, R. Y. (1987). Associative positioning strategies through comparative advertising: Attribute versus overall similarity approaches. Journal of Marketing Research, 24, 377-388.

Giese, J. L., \& Sojka, J. Z. (1998). The relationship between processing styles and self-control behavioral characterisics. Marketing Letters, 9, 371-382.

Gorn, G. J., \& Weinberg, C. B. (1984). The impact of comparative advertising on perception and attitude: Some positive findings. Journal of Consumer Research, 11, 719727.

Haugtvedt, C. P., \& Petty, R. E. (1989). Need for cognition and attitude persistence. Advances in Consumer Research, 16, 33-36.

Haugtvedt, C. P., Petty, R. E., \& Cacioppo, J. T. (1992). Need for cognition and advertising: Understanding the role of personality variables in consumer behavior. Journal of Consumer Psychology, 1, 239-260.

Haugtvedt, C. P., Petty, R. E., Cacioppo, J. T., \& Steidley, T. (1988). Personality and ad effectiveness: Exploring the utility of need for cognition. Advances in Consumer Research, $15,209-212$.

Herr, P. M. (1986). Consequences of priming: Judgment and behavior. Journal of Personality and Social Psychology, 51, 1106-1115.

Herr, P. M., Sherman, S. J., \& Fazio, R. H. (1983). On the consequences of priming: Assimilation and contrast effects. Journal of Experimental Psychology, 19, 323-340.

Higgins, T. E., Rholes, W. S., \& Jones, C. R. (1977). Category accessibility and impression formation. Journal of Experimental Social Psychology, 13, 141-154.

Hsee, C. (1996). The evaluability hypothesis: An explanation for preference reversals between joint and separate evaluations of alternatives. Organizational Behavior and Human Decision Processes, 67, 247-257.

Hsee, C. K., \& Leclerc, F. (1998). Will products look more attractive when presented separately or together? Journal of Consumer Research, 25(2), 175-186.

Huber, J., Payne, J. W., \& Puto, C. (1982). Adding asymmetrically dominated alternatives: Violations of regularity and the similarity hypothesis. Journal of Consumer Research, 9, 90-98.

Huber, J., \& Puto, C. (1983). Market boundaries and product choice: Illustrating attraction and substitution effects. Journal of Consumer Research, 10, 31-44.

Janiszewski, C. A., Silk, T., \& Cooke, A. D. J. (2003). Different scales for different frames: The role of subjective scales and experience in explaining attribute-framing effects. Journal of Consumer Research, 30, 311-327. 
Kardes, F., \& Sanbonmatsu, D. M. (2003). Omission neglect: The importance of missing information. Skeptical Inquirer, 27, 42-46.

Kenrick, D. T., \& Gutierres, S. E. (1980). Contrast effects and judgments of physical attractiveness: When beauty becomes a social problem. Journal of Personality and Social Psychology, 38, 131-140.

Kenrick, D. T., Gutierres, S. E., \& Goldberg, L. L. (1989). Influence of popular erotica on judgments of strangers and mates. Journal of Experimental Social Psychology, 25, 159167.

Lafferty, B. A. (2009). Selecting the right cause partners for the right reasons: The role of importance and fit in causebrand alliances. Psychology \& Marketing, 26, 359-382.

Lerner, J. S., \& Tetlock, P. E. (1999). Accounting for the effects of accountability. Psychological Bulletin, 125, 255275.

Levin, I. P., \& Levin, A. M. (2000). Modeling the role of brand alliances in the assimilation of product evaluations. Journal of Consumer Psychology, 9, 43-52.

Loken, B., \& John, D. R. (1993). Diluting brand beliefs: When do brand extensions have a negative impact? Journal of Marketing, 57, 71-84.

Lombardi, W. J., Higgins, T. E., \& Bargh, J. A. (1987). The role of consciousness in priming effects on categorization: Assimilation versus contrast as a function of awareness of the priming task. Personality and Social Psychology Bulletin, 13, 411-429.

Manning, K. C., Miniard, P. W., Barone, M. J., \& Rose, R. L. (2001). Understanding the mental representations created by comparative advertising. Journal of Advertising, 30, 2739.

Martin, L. L. (1986). Set/ reset: Use and disuse of concepts in impression formation. Journal of Personality and Social Psychology, 51, 493-504.

Martin, L. L., Seta, J. L., \& Crelia, R. A. (1990). Assimilation and contrast as a function of people's willingness and ability to expend effort in forming an impression. Journal of Personality and Social Psychology, 59, 27-37.

Markman, A. B., \& Gentner, D. (1993). Structural alignment during similarity comparisons. Cognitive Psychology, 25, 431-467.

McGuire, W. J. (1981). The probabilogical model of cognitive structure and attitude change. In R. E. Petty, T. M. Ostrom, $\&$ T. C. Brock (Eds.), Cognitive responses in persuasion (pp. 291-308). Hillsdale, NJ: Lawrence Erlbaum.

Miniard, P. W., Rose, R. L., Manning, K. C., \& Barone, M. J. (1998). Tracking the effects of comparative and noncomparative advertising with relative and nonrelative measures: A further examination of the framing correspondence hypothesis. Journal of Business Research, 41, 137-143.

Miyazaki, A. D., Grewal, D., \& Goodstein, R. C. (2005). The Effect of multiple extrinsic cues on quality perceptions: A matter of consistency. Journal of Consumer Research, 32, 146-153.

Mussweiler, T. (2003). Comparison processes in social judgment: Mechanisms and consequences. Psychological Review, 110, 472-489.

Nowlis, S. M., \& Simonson, I. (1997). Attribute-task compatibility as a determinant of consumer preference reversals. Journal of Marketing Research, 34, 205-218.

Park, C. W., Jun, S. Y., \& Shocker, A. D. (1996). Composite branding alliances: An investigation of extension and feedback effects. Journal of Marketing Research, 33, 453-466.

Peck, J., \& Loken, B. (2004). When will larger-sized female models in advertisements be viewed positively? The mod- erating effects of instructional frame, gender, and need for cognition. Psychology \& Marketing, 21, 425-442.

Petty, R. E, Cacioppo, J. T., Haugtvedt, C. P., \& Heesacker, M. (1993). Consequences of the route to persuasion: Persistence and resistance of attitude changes. Unpublished manuscript, University of Missouri, Columbia, MO.

Petty, R. E., DeMarree, K. G., Briñol, P., Horcajo, J., \& Strathman, A. J. (2008). Need for cognition can magnify or attenuate priming effects in social judgment. Personality and Social Psychology Bulletin, 34, 900-912.

Petty, R. E., \& Jarvis, W. B. G. (1996). An individual differences perspective on assessing cognitive processes. In N. Schwarz \& S. Sudman (Eds.), Answering questions: Methodology for determining cognitive and communicative processes in survey research (pp. 221-257). San Francisco, CA: Jossey-Bass.

Petty, R. E., Schumann, D. W., Richman, S. A., \& Strathman, A. J. (1993). Positive mood and persuasion: Different roles for affect under high and low elaboration conditions. Journal of Personality and Social Psychology, 64, 5-20.

Rao, A. R., \& Ruekert, R. W. (1994). Brand alliances as signals of product quality. Sloan Management Review, 87-97.

Rao, A. R., Qu, L., \& Ruekert, R. W. (1999). Signaling unobservable product quality through a brand ally. Journal of Marketing Research, 36, 258-268.

Rose, R. L., \& Miniard, P. W., Barone, M. J., Manning, K. C., \& Till, B. D. (1993). When the persuasion goes undetected: The case of comparative advertising. Journal of Marketing Research, 30, 315-331.

Schwarz, N., \& Bless, H. (1992). Constructing reality and its alternatives: An inclusion/exclusion model of assimilation and contrast effects in social judgment. In L. L. Martin \& A. Tesser (Eds.), The construction of social judgments (pp. 217-245). Hillsdale, NJ: Lawrence Erlbaum Associates.

Shimp, T. A., \& Dyer, D. C. (1978). The effects of comparative advertising mediated by market position of sponsoring brand. Journal of Advertising, 7, 13-19.

Simonin, B. L., \& Ruth, J. A. (1998). Is a company known by the company it keeps? Assessing the spillover effects of brand alliances. Journal of Marketing Research, 35, 30-42.

Simonson, I., \& Tversky, A. (1992). Choice in context: Tradeoff contrast and extremeness aversion. Journal of Marketing Research, 29, 281-295.

Slovic, P., \& MacPhillamy, D. (1974). Dimensional commensurability and cue utilization in comparative judgment. Organizational Behavior \& Human Performance, 11, 172-194.

Smith, S. M., Haugtvedt, C. P., \& Petty, R. E. (1994). Need for cognition and the effects of repeated expression on attitude accessibility and extremity. Advances in Consumer Research, 22, 234-237.

Sujan, M., \& Dekleva, C. (1987). Product categorization and inference making: Some implications for comparative advertising. Journal of Consumer Research, 14, 372-378.

The Wall Street Journal. (1991). H\&R Block, Excedrin discover joint promotions can be painful. February 28, B3.

Walchli, S. B. (2007). The effects of between-partner congruity on consumer evaluation of co-branded products. Psychology and Marketing, 24, 947-973.

Wänke, M., Bless, H., \& Igou, E. R. (2001). Next to a star: Paling, shining, or both? Turning interexemplar contrast into interexemplar assimilation. Personality and Social Psychology Bulletin, 27, 14-29.

Wedell, D. H. (1991). Distinguishing among models of contextually induced preference reversals. Journal of Experimental Psychology: Learning, Memory, and Cognition, 17, 767-778. 
Wedell, D. H., Hicklin, S. M., \& Smarandescu, L. (2007). Contrasting models of assimilation and contrast. In D. Stapel \& J. Suls (Eds.), Assimilation and contrast in social psychology. New York: Psychology Press.

Wedell, D. H, Parducci, A., Geiselman, E. R. (1987). A formal analysis of ratings of physical attractiveness: Successive contrast and simultaneous assimilation. Journal of Experimental Social Psychology, 23, 230-249.

Yadav, M. (1994). How buyers evaluate product bundles: A model of anchoring and adjustment. Journal of Consumer Research, 21, 342-353.

Zhang, S., Kardes, F. R., \& Cronley, M. L. (2002). Comparative advertising: Effects of structural alignability on target brand evaluations. Journal of Consumer Psychology, 12, 303-311.
Zhang, S., \& Markman, A. B. (1998). Overcoming the early entrant advantage: The role of alignable and nonalignable differences. Journal of Marketing Research, 35, 413426.

Zhang, S., \& Markman, A. B. (2001). Processing product unique features: Alignability and involvement in preference construction. Journal of Consumer Psychology, 11, $13-27$.

Correspondence regarding this article should be sent to: Laura Smarandescu, 3254 Gerding Building, Department of Marketing, College of Business, Iowa State University, Ames, Iowa, 50011 (smarand@iastate.edu). 